\title{
Inhibitory activity of blasticidin A, a strong aflatoxin production inhibitor, on protein synthesis of yeast: selective inhibition of aflatoxin production by protein synthesis inhibitors
}

\author{
Tomoya Yoshinari ${ }^{1}$, Yoichi Noda ${ }^{2}, K_{0 j i}$ Yoda $^{2}$, Hiroshi Sezaki ${ }^{3}$, Hiromichi Nagasawa ${ }^{1}$ and Shohei Sakuda ${ }^{1}$ \\ Blasticidin $\mathrm{A}(\mathrm{BCA})$, an antibiotic produced by Streptomyces, inhibits aflatoxin production without strong growth inhibition \\ toward aflatoxin-producing fungi. During the course of our study on the mode of action of BcA by two-dimensional differential \\ gel electrophoresis (2D-DIGE), we found a decrease in the abundances of ribosomal proteins in Saccharomyces cerevisiae \\ after exposure to BcA. This phenomenon was also observed by treatment with blasticidin $\mathrm{S}(\mathrm{BcS})$ or cycloheximide. BcA \\ inhibited protein synthesis in a galactose-induced expression system in S. cerevisiae similar to BcS and cycloheximide. \\ BcS, but not cycloheximide, inhibited aflatoxin production in Aspergillus parasiticus without inhibition of fungal growth, \\ similar to BcA. A decrease in the abundances of aflatoxin biosynthetic enzymes was observed in 2D-DIGE experiments with \\ Aspergillus flavus after exposure to $\mathrm{BcA}$ or $\mathrm{BcS}$. These results suggested that protein synthesis inhibitors are useful to control \\ aflatoxin production.
}

The Journal of Antibiotics (2010) 63, 309-314; doi:10.1038/ja.2010.36; published online 23 April 2010

Keywords: aflatoxin; blasticidin A; blasticidin S

\section{INTRODUCTION}

Aflatoxins are a group of mycotoxins with potent toxicity and carcinogenicity in mammals. Some strains of Aspergillus sp. produce aflatoxins that are found as contaminants in a wide variety of food and feed commodities. Aflatoxin contamination in agricultural products is a serious problem in terms of not only food safety but also economic loss. ${ }^{1,2}$ However, it is difficult to resolve the problem due to lack of an effective method to control aflatoxin production.

We have been studying specific inhibitors of aflatoxin production based on the idea that they may be useful to prevent foods and feeds from aflatoxin contamination without incurring a rapid spread of resistant strains. ${ }^{3}$ Blasticidin $\mathrm{A}(\mathrm{BCA})$ was found as an antibiotic produced by Streptomyces griseochromogenes, but its structure had not been known. ${ }^{4,5}$ We found that BcA strongly inhibited production of both aflatoxin B and G groups by Aspergillus parasiticus, and we determined its structure, ${ }^{6,7}$ which is similar to that of aflastatin $A$, an aflatoxin production inhibitor produced by Streptomyces $\mathrm{sp}^{8}{ }^{8} \mathrm{BcA}$ and aflastatin A reduced the mRNA levels of genes encoding aflatoxin biosynthetic enzymes and a key regulatory protein, AflR. ${ }^{9,10}$ Therefore, they may affect a pathway leading to expression of aflatoxin biosynthetic enzymes.

$\mathrm{BcA}$ inhibited aflatoxin production of $A$. parasiticus without significantly disturbing the fungal growth at low concentrations, but inhibition of the fungal growth was observed at higher concentrations. This suggested that aflatoxin production inhibitory activity of BcA might be correlated with its antifungal activity. BcA showed antimicrobial activity toward Saccharomyces cerevisiae. ${ }^{10}$ Our attempt to obtain BcA-resistant strains by transformation of $S$. cerevisiae with cDNA or genomic libraries has not afforded critical candidate genes for investigating a target molecule (data not shown). Therefore, analysis of the yeast proteome by two-dimensional differential gel electrophoresis (2D-DIGE) $)^{11}$ was performed. There are many works on proteome of S. cerevisiae ${ }^{12}$ and alterations in protein abundance levels can provide clues about the mechanism of action of various drugs. ${ }^{13}$ However, it is still difficult to estimate the target molecule of a drug from proteome information alone. In this study, we found relationship between protein synthesis inhibition and decrease of abundances of ribosomal proteins in S. cerevisiae. We also performed 2D-DIGE analysis with Aspergillus flavus and showed decrease of abundances of aflatoxin biosynthetic enzymes by treatment with some aflatoxin production inhibitors.

In this paper, we report inhibitory activity of $\mathrm{BcA}$ on protein synthesis of $S$. cerevisiae and selective inhibition of aflatoxin production of Aspergillus sp. by some protein synthesis inhibitors.

${ }^{1}$ Department of Applied Biological Chemistry, University of Tokyo, Tokyo, Japan; ${ }^{2}$ Department of Biotechnology, University of Tokyo, Tokyo, Japan and ${ }^{3}$ Application Center, Agilent Technologies Japan, Tokyo, Japan

Correspondence: Dr S Sakuda, Department of Applied Biological Chemistry, University of Tokyo, 1-1-1 Yayoi, Bunkyo-ku, Tokyo 113-8657, Japan.

E-mail: asakuda@mail.ecc.u-tokyo.ac.jp

Received 26 January 2010; revised 25 February 2010; accepted 26 March 2010; published online 23 April 2010 


\section{MATERIALS AND METHODS}

Strains, growth media and chemicals

S. cerevisiae strain W303, A. parasiticus NRRL2999 and A. flavus IMF47798 were used. Details of culture conditions are described in Supplementary information. Analysis of growth and aflatoxin production was performed as described earlier. ${ }^{14}$

BcA (purified from the culture broth of S. griseochromogenes IFO13413, purity $>98 \%$ determined by HPLC), rapamycin (Sigma-Aldrich, St Louis, MO, USA) and amphotericin B (Wako, Osaka, Japan) were dissolved in dimethyl sulfoxide. Cycloheximide (Nacalai tesque, Kyoto, Japan), G418 (Invitrogen, Carlsbad, CA, USA) and blasticidin S (BcS) (Invitrogen) were dissolved in distilled water.

\section{Sample preparation for 2D-DIGE analysis}

S. cerevisiae cells were cultured overnight and diluted to an $\mathrm{OD}_{600}$ of 0.4 , and then cultured for $1 \mathrm{~h}$. A test drug was added to the cultures, followed by $30 \mathrm{~min}$ incubation. In the case of A. flavus, a spore suspension of the fungus $(10 \mu \mathrm{l})$ was added to a Potato Dextrose (Becton, Dickinson and Company, Sparks, MD, USA) medium $(10 \mathrm{ml})$ with $\mathrm{BcA}(0.3 \mu \mathrm{M})$ or $\mathrm{BcS}(300 \mu \mathrm{M})$ in a $100 \mathrm{ml}$ Erlenmeyer flask and incubated. After 24 or $36 \mathrm{~h}$, mycelia were harvested and lyophilized. Total proteins of the yeast cells or fungal mycelia were extracted using CelLytic Y Yeast Cell Lysis/Extraction Reagent (Sigma-Aldrich) with protease inhibitor cocktail EDTA-free (Roche, Basel, Switzerland) and phosphatase inhibitor cocktail (Sigma-Aldrich). Protein samples were precipitated with acetone and treated with 2D-DIGE lysis buffer ( $2 \mathrm{~m}$ thiourea, $7 \mathrm{~m}$ urea, $4 \%$ (w/v) CHAPS, $30 \mathrm{~mm}$ Tris-HCl, $\mathrm{pH}$ 8.5). Total protein contents were determined by the Bradford assay using BSA as a standard.

\section{Fluorescence labeling with Cy-Dyes}

Drug-treated and control samples were quantified and labeled with NHS-Cy2, -Cy3 and Cy5 (GE Healthcare, Buckinghamshire, UK). Protein $(50 \mu \mathrm{g})$ taken from drug-treated or control samples were minimally labeled with $160 \mathrm{pmol}$ of Cy3 or Cy5 in triplicate. An equal pool of drug-treated and control samples were labeled with Cy2 (3.2 $\mathrm{pmol}^{\mathrm{\mu g}} \mathrm{g}^{-1}$ protein) and run as a standard on all gels to aid in spot matching and cross-gel quantitative analysis. Protein labeling was performed on ice in the dark for $30 \mathrm{~min}$. Reactions were quenched by $10 \mathrm{~min}$ incubation with a 20 -fold molar excess of free lysine. The labeled samples were mixed and carrier Pharmalyte ( $\mathrm{pH} 3-10$, GE Healthcare) was added to a final concentration of $2 \%$.

\section{D-gel electrophoresis}

Control, drug-treated and internal standard samples labeled with Cy3, Cy5 and Cy2, respectively, were mixed and separated by isoelectric focusing in the first dimension using $24 \mathrm{~cm} \mathrm{pH} \mathrm{3-10} \mathrm{NL} \mathrm{(nonlinear)} \mathrm{or} \mathrm{3-5.6} \mathrm{NL} \mathrm{IPG} \mathrm{strip}$ (GE Healthcare) and by SDS-PAGE in the second dimension using $10 \%$ SDS-PAGE gel bonded to low-fluorescence glass plates. Gels were run in Ettan 6 (GE Healthcare) gel tanks at $400 \mathrm{~mA}$ per gel at $20^{\circ} \mathrm{C}$ until the dye front had run off the bottom.

\section{Image acquisition and biological variance analysis}

After 2D-gel electrophoresis, gels were scanned using a Typhoon 9400 variable mode imager (GE Healthcare) and ImageQuant software (GE Healthcare). The photomultiplier tube voltage was adjusted for each dye channel for preliminary low-resolution scans to give maximum pixel values within $5-10 \%$ for each channel and below saturation, before the acquisition of $100 \mu \mathrm{m}$ high-resolution images. Images were cropped and analyzed using DeCyder V5.0 (GE Healthcare). Ratios of spot intensities detected in drug-treated or control samples to those of corresponding spots in standard sample were calibrated and obtained values were averaged across triplicates for each experimental condition. Statistical analysis was performed to pick spots matching across all images, displaying a $\geqslant 1.4$ (in experiments with $S$. cerevisiae) or 1.5 (in experiments with $A$. flavus) average-fold increase or decrease in abundance between drugtreated and control samples and with $P$-values $<0.05$ (Student's $t$-test).
In-gel digestion and protein identification by mass spectrometry Visible spots were excised from the CBB R250 (Nacalai tesque)-stained gels and transferred into microcentrifuge tubes. Excised fragments were washed successively with water, $25 \mathrm{~mm} \mathrm{NH}_{4} \mathrm{HCO}_{3}$, acetonitrile per $25 \mathrm{mM} \mathrm{NH}_{4} \mathrm{HCO}_{3}$ (1:1) and acetonitrile. Destained gel fragments were dried under vacuum with a centrifugal evaporator. Tryptic digestion was performed overnight at $37^{\circ} \mathrm{C}$ using $10 \mu \mathrm{l}$ of $10 \mu \mathrm{g} \mathrm{ml}^{-1}$ trypsin (Roche) in $50 \mathrm{~mm} \mathrm{NH}_{4} \mathrm{HCO}_{3}, \mathrm{pH}$ 7.8. The resulting tryptic fragments were extracted twice with $100 \mu \mathrm{l}$ of acetonitrile/ water $(3: 2)$ containing $0.1 \%$ TFA, in an ultrasonic bath for $15 \mathrm{~min}$. The supernatants were concentrated to $10 \mu \mathrm{l}$ in a centrifugal evaporator and subjected to LC-MS/MS analysis. The concentrated solutions were passed through a Zip-Tip C18 (Millipore, Bedford, MA, USA). The adsorbed peptides were eluted with $2.0 \mu \mathrm{l}$ of acetonitrile/water (3:2) containing $0.1 \%$ TFA and $1 \%$ $\alpha$-cyano-4-hydroxycinnamic acid. The eluent was loaded onto a mass spectrometer sample plate. Mass spectra were acquired on a Voyager-DE STR MALDITOF mass spectrometer (Applied Biosystems, Foster City, CA, USA) operated in the reflectron-delayed extraction mode. Spectra were internally calibrated using trypsin autodigestion products. MASCOT (Matrix Science, Boston, MA, USA) was used to search databases. The expect value, number of matched peptides and percentage of sequence coverage for each identified protein are listed in Tables 1 and 2. A. flavus proteins in spots 6, 8 and 12 (Supplementary Figure S2; Table 2) were identified by LC-MS/MS analysis according to the methods in Supplementary information.

\section{Protein synthesis inhibitory activity of BcA}

Strain w303 was freshly transformed with plasmid pYES2-6 $\times$ His-LacZ (Invitrogen) and grown overnight in SD-ura raffinose media. This culture was diluted to an $\mathrm{OD}_{600}$ of 1.0. A test compound and $600 \mu \mathrm{l}$ of SD-ura galactose media were added to $2.4 \mathrm{ml}$ of the diluted culture. The cells were incubated for $60 \mathrm{~min}$ and harvested, and total protein extractions were performed as described above. After acetone precipitation, the extracted proteins were re-suspended in SDS-PAGE sample buffer $(65 \mathrm{~mm}$ Tris-HCl, $\mathrm{pH} 6.8,2 \%$ SDS, $10 \%$ glycerol, $5 \%$ 2-mercaptoethanol, $0.002 \%$ bromophenol blue). Proteins were separated on 7.5\% SDS-PAGE gels and transferred to a PVDF membrane. The membrane was probed using an anti- $6 \times$ His-tag antibody (BioDynamics Laboratory, Tokyo, Japan) and visualized by using immobilon Western Chemiluminescent HRP Substrate (Millipore).

\section{RESULTS AND DISCUSSION}

\section{Effects of BcA on S. cerevisiae proteome}

S. cerevisiae was incubated without or with $\mathrm{BcA}(1 \mu \mathrm{M}$ corresponding to MIC) for $30 \mathrm{~min}$ and the proteins were extracted from the cells. The control and BcA samples were labeled with green and red dyes, respectively, and combined. The mixture was separated by $2 \mathrm{D}$-gel electrophoresis followed by fluorescent imaging (Figure 1). Five green (spots 1, 2, 3, 4 and 5) and one red (spot 6) spots, showing changes in abundance $>1.4$-fold, were clearly observed by using the gel with a $\mathrm{pH}$ range of 3-10 (Figure 1a). A better separation of spots 7, 8, 9 and 10 was obtained using a $\mathrm{pH}$ range of 3-5.6 (Figure 1b). Proteins in spots 1, 2, 3, 4 and 5 (decreased with BcA treatment) and spot 6 (increased with BcA treatment) were identified by MALDI-TOF MS analysis after in-gel tryptic digestion as ribosomal proteins (Rpp0p, Rps0Ap, Rps0Bp, Asclp and Rps5p) and glycerol-3-phosphate dehydrogenase (Gpd1p) (Table 1). Results of the MASCOT search analysis on proteins in spots $7 \mathrm{a}, 8 \mathrm{a}, 9 \mathrm{a}$ and $10 \mathrm{a}$ showed that they were the same as those in spots $7 \mathrm{~b}, 8 \mathrm{~b}, 9 \mathrm{~b}$ and $10 \mathrm{~b}$, respectively. The proteins were identified as translational factors (Sup45p and Tif5p) and molecular chaperones (Pdr13p and Cdc37p) (Table 1).

In all these paired spots, increase of the levels of protein molecules with lower isoelectronic points and concomitant decrease of those with higher ones were observed. MS analysis of spot $8 \mathrm{~b}$ yielded an $(\mathrm{M}+\mathrm{H})^{+}$ion peak for a trypsinized peptide corresponding to amino-acid residues 383-405 of Tif5p at $m / z 2682.43$ (Supplementary Figure S1a). In contrast, MS analysis of spot 8 a yielded an ion peak 


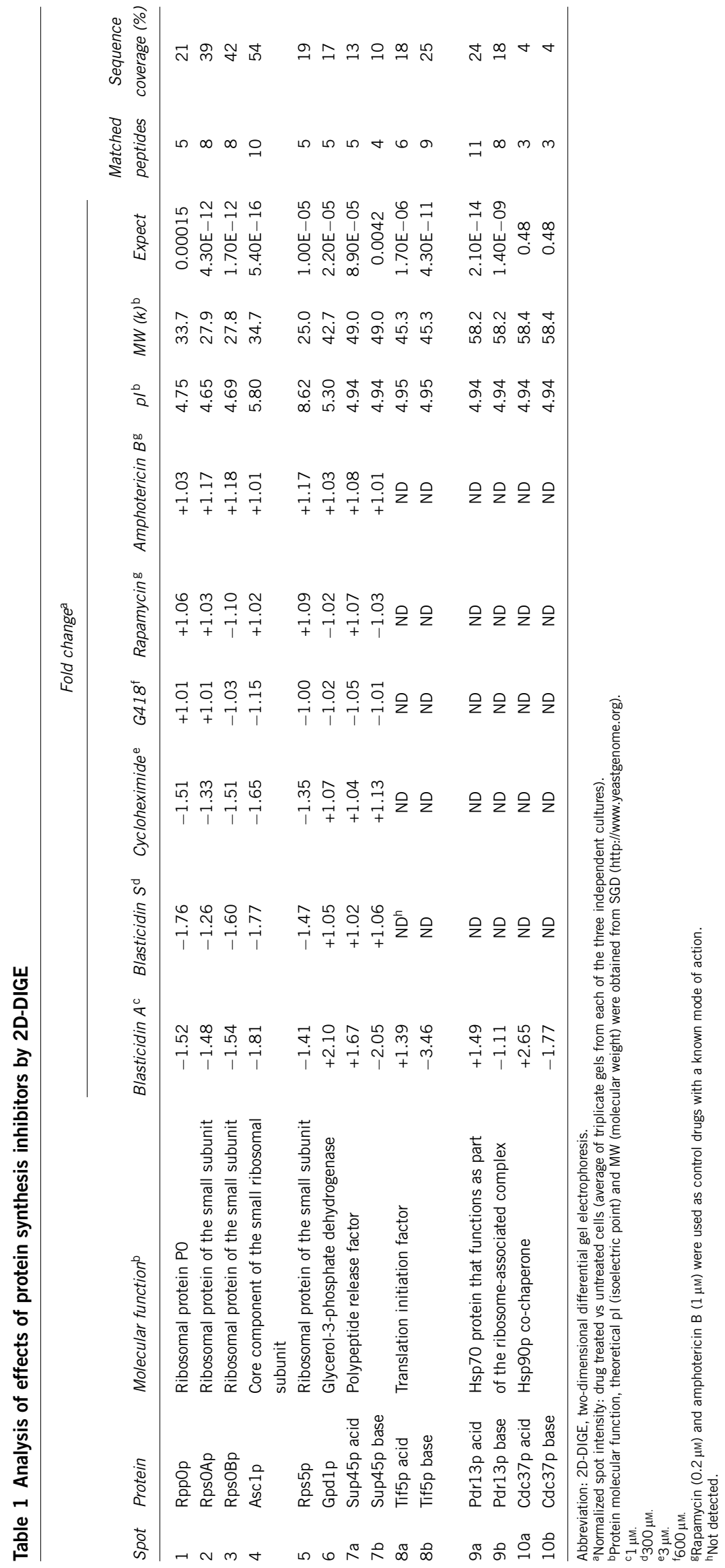


Table 2 Identification of protein spots in 2D-DIGE experiments with blasticidin A and blasticidin S treated A. flavus cells

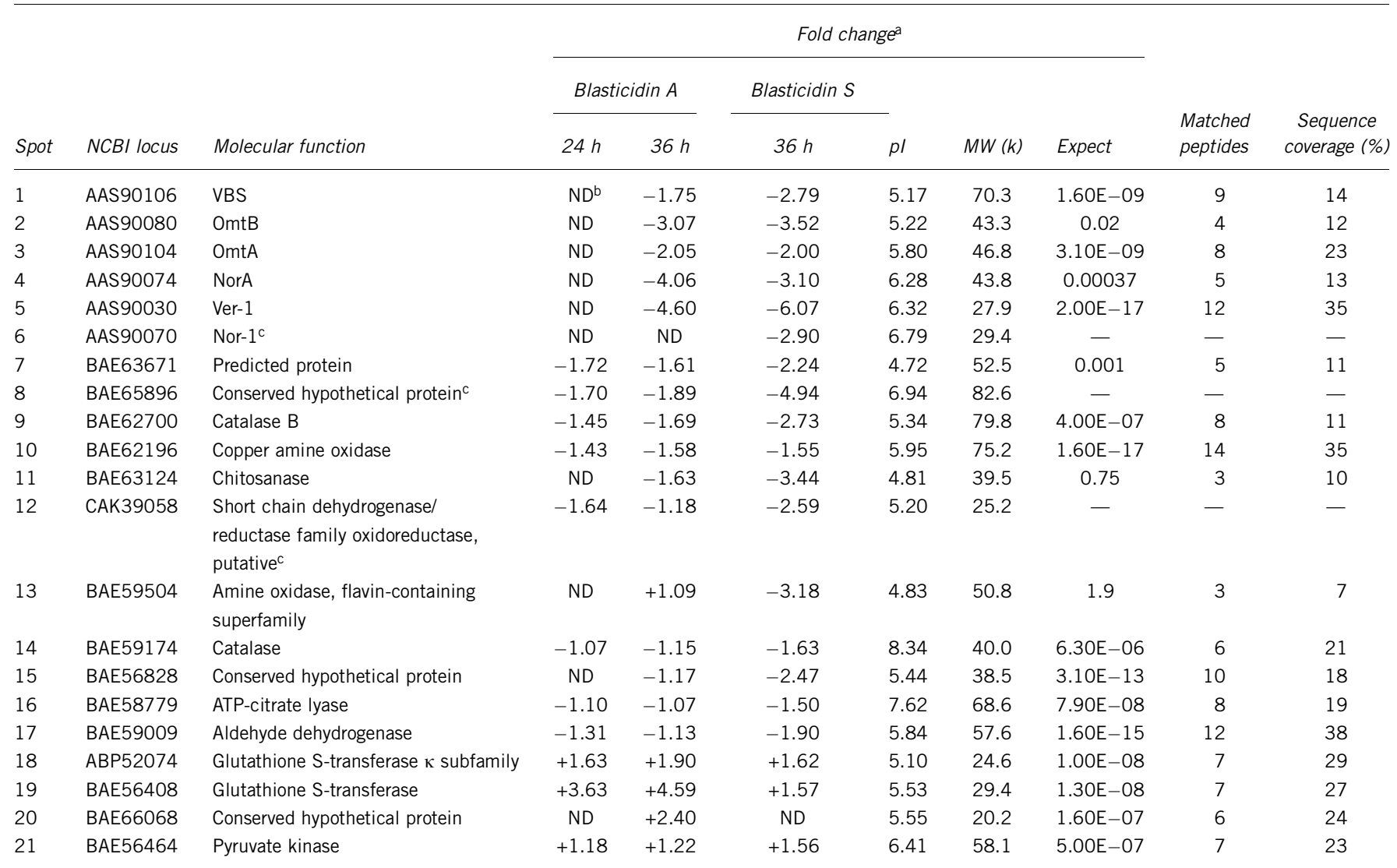

Abbreviation: 2D-DIGE, two-dimensional differential gel electrophoresis.

a Normalized spot intensity: blasticidin A or blasticidin S treated vs untreated cells (average of triplicate gels from each of the three independent cultures). bNot detected.

cIdentified by amino-acid sequences from LC-MS/MS analysis.

at $m / z 2762.72$ instead of $m / z 2682.43$ (Supplementary Figure S1b). Ser-397 of Tif5p is a possible phosphorylation site. These results suggested that the acidic nature of Tif5p in spot $8 \mathrm{a}$ was due to phosphorylation and that BcA may promote phosphorylation of Tif5p. Phosphorylation of Tif5p is catalyzed by protein kinase CK2. ${ }^{15}$ CK2 phosphorylates a variety of substrate proteins including Sup45p and Cdc37p. ${ }^{16}$ Therefore, phosphorylation of Sup $45 p$ and Cdc37p may be promoted by BcA when BcA activates CK2.

\section{Effects of BcA on gene transcription}

Quantitative PCR analysis was performed to examine the effect of BcA on the transcription of genes encoding the proteins whose abundance levels were altered by BcA treatment. S. cerevisiae cells were treated with $\mathrm{BcA}(1 \mu \mathrm{M})$ or rapamycin $(0.2 \mu \mathrm{M}$ corresponding to $\mathrm{MIC})$. Rapamaycin reduces transcription of genes encoding ribosomal proteins. ${ }^{17}$ The mRNA levels of ribosomal protein genes, ASC1 and $R P P 0$, were reduced by rapamycin, but were not affected by $\mathrm{BcA}$ (Figures $2 \mathrm{a}$ and $\mathrm{b}$ ), indicating that $\mathrm{BcA}$ decreased abundance levels of these ribosomal proteins without affecting transcription. On the other hand, the mRNA level of GPD1 was clearly increased by BcA (Figure 2c).

Gpd1p is an enzyme required for glycerol synthesis and mRNA level of GPD1 is upregulated by high osmotic stress. ${ }^{18}$ Phosphorylation of $\mathrm{Cdc} 37 \mathrm{p}$ is important in the high osmotic stress signal transduction pathway that leads to glycerol synthesis. ${ }^{19}$ Therefore, increase of levels of Gpd1p and phosphorylated Cdc37p by BcA treatment suggested that BcA might affect the high osmotic stress signal transduction pathway by increasing Cdc37p phosphorylation.

\section{Effects of BcA on protein synthesis in S. cerevisiae}

The protein synthesis inhibitory activity of BcA was examined as most proteins identified in the 2D-DIGE experiments were involved in protein translation. S. cerevisiae was transformed with a plasmid containing the GAL1 promoter and histidine-tagged $\beta$-galactosidase $(6 \times$ His-LacZ) gene. The transformed cells did not produce $6 \times$ His$\mathrm{LacZ}$ protein in a medium containing glucose or raffinose due to glucose repression of the GAL1 promoter (Figure 3, lane A). Induction of $6 \times$ His-LacZ protein synthesis was observed when cells having been cultured in a raffinose medium were inoculated into a medium with galactose (lane B). In this galactose-induction protein synthesis system, eukaryotic protein synthesis inhibitors, cycloheximide and $\mathrm{BcS}$, clearly inhibited synthesis of $6 \times$ His-LacZ protein (lanes $\mathrm{F}$ and $\mathrm{H})$, but amphotericin B had no effect (lane G). Similarly to cycloheximide and $\mathrm{BcS}, \mathrm{BcA}$ inhibited $6 \times$ His-LacZ protein synthesis dose dependently (lanes $\mathrm{C}, \mathrm{D}$ and $\mathrm{E}$ ). This strongly suggested that BcA has inhibitory activity toward protein synthesis in S. cerevisiae.

\section{Effects of protein synthesis inhibitors on S. cerevisiae proteome} Next, we examined the effect of known protein synthesis inhibitors on the S. cerevisiae proteome. S. cerevisiae cells were treated with the MIC concentration of three inhibitors effective in eukaryote, cycloheximide, $\mathrm{BcS}$ and G418, and rapamycin for $30 \mathrm{~min}$. Cycloheximide and BcS 

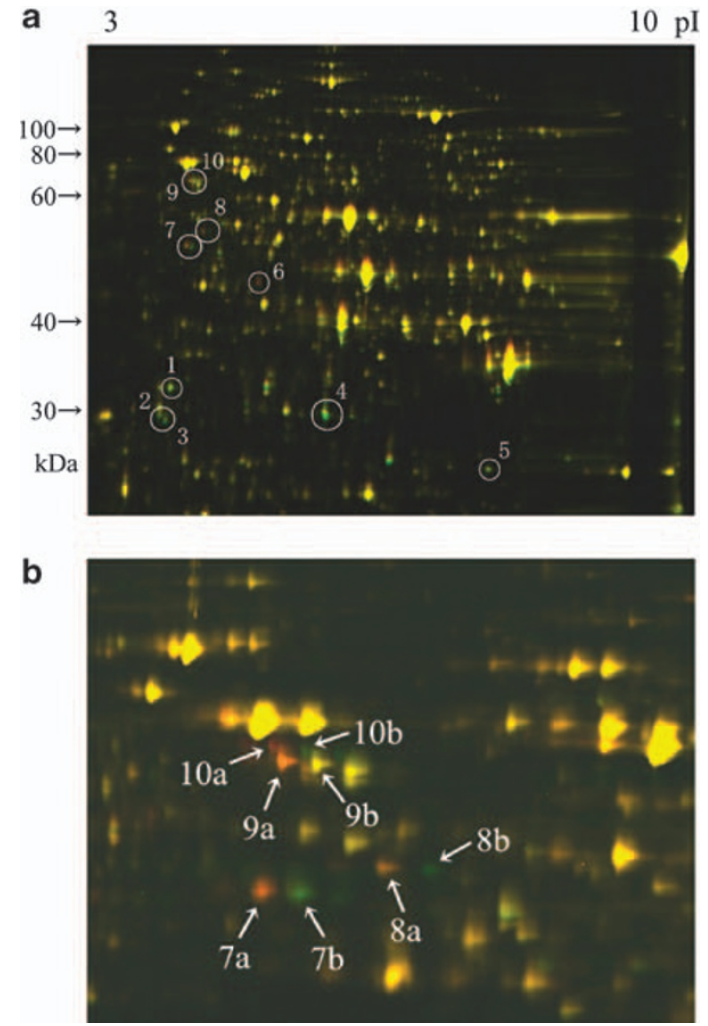

Figure 1 2D-DIGE gel image of $S$. cerevisiae proteome after blasticidin A treatment. (a) pl range 3-10. (b) pl range 3-5.6. Green, red and yellow spots indicate proteins with decreased, increased or unchanged abundance levels, respectively. Selected proteins ( $>1.4$ and $<-1.4$ change in abundance; $P<0.05 ; n=3$ ) are numbered.

decreased abundances of the same five ribosomal proteins as BcA (Table 1). The speed of synthesis of ribosomal proteins is known to be fastest among all proteins in yeast. ${ }^{20}$ Therefore, reduction of ribosomal proteins might be observed more remarkably than others when protein synthesis is inhibited. Rapamycin and G418 did not affect abundance levels of the ribosomal proteins including Asclp and Rpp0p with the short time treatment conditions used in this study. Abundance levels of Sup45p and Gpd1p were not affected by cycloheximide, BcS, G418 or rapamycin, but were affected by BcA mentioned above. Tif5p, Sup45p and Pdr13 $\mathrm{p}^{21}$ are important factors for translation in S. cerevisiae, but phosphorylation of Tif5p and Sup $45 p^{22}$ is not essential for ribosomal function of the yeast and there is no information on phosphorylation of Pdr13p. Therefore, it is unclear whether increased levels of phosphorylated Tif5p, Sup45p or Pdr13p resulting from $\mathrm{BcA}$ treatment is correlated with protein synthesis inhibition.

\section{Aflatoxin production inhibitory activity of protein synthesis inhibitors}

The effects of protein synthesis inhibitors on aflatoxin production were examined. A. parasiticus was cultured in a liquid medium containing a test compound. The weight of fungal mycelia and aflatoxin content in the culture broth were measured (Table 3). The ratio of $\mathrm{IC}_{50}$ for growth inhibition based on mycelial weight to aflatoxin production inhibition was used as an indicator of specificity for aflatoxin production inhibition (shown as g/a values in Table 3). $\mathrm{BcA}$ was the strongest inhibitor of aflatoxin production with relatively high selectivity (g/a 6.4). BcS and G418 were also shown to be specific
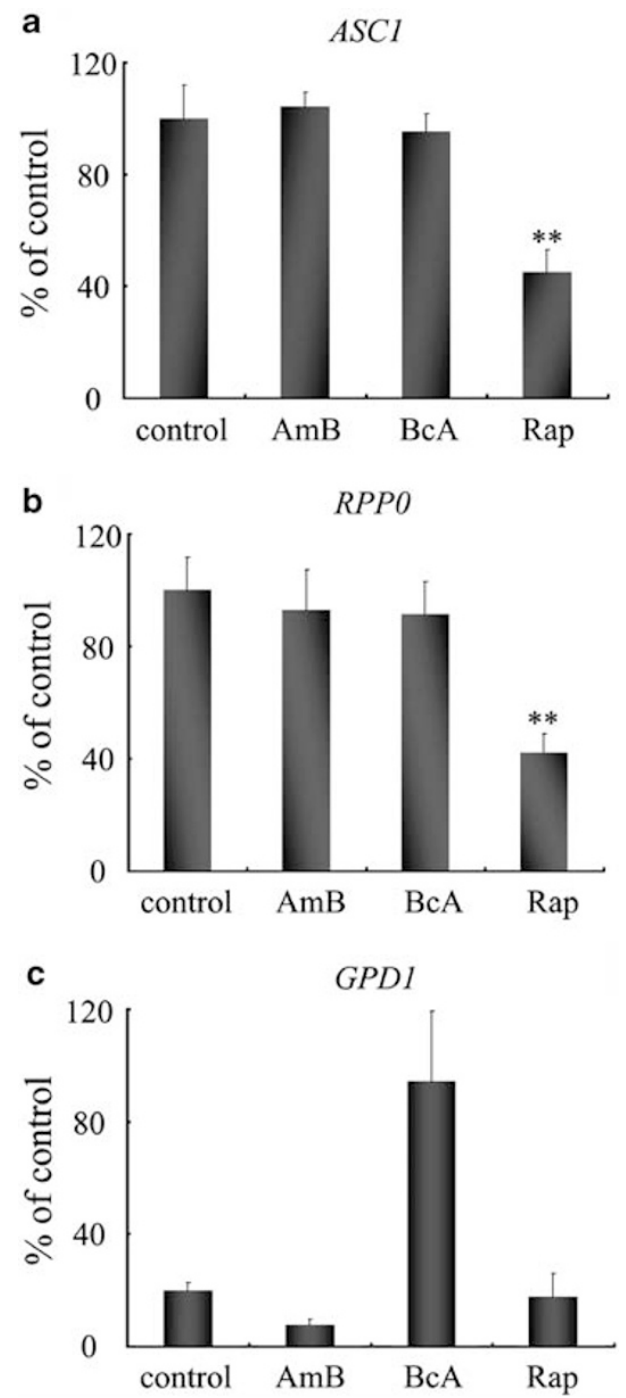

Figure 2 Effects of blasticidin A on transcription of $A S C 1$ (a), RPPO (b) and GPD1 (c). Total RNA was prepared from yeast that had been cultured in a YPD liquid medium with or without BcA $(1 \mu \mathrm{m})$, amphotericin B (AmB, $1 \mu \mathrm{m}$ ) or rapamycin (Rap, $0.2 \mu \mathrm{m}$ ) for $30 \mathrm{~min}$. AmB was used as a control drug with a known mode of action. The amount of each mRNA was normalized by the amount of $\beta$-actin mRNA in each sample. Data are presented as the mean \pm s.d. $(n=3) . * * P<0.01$, vs control (one-way analysis of variance, followed by Dunnett test).

aflatoxin production inhibitors (g/a $>36$ and 8.0, respectively). Especially, BcS had very high selectivity. Cycloheximide inhibited both mycelial growth and aflatoxin production without selectivity (g/a 1.4). Chloramphenicol, neomycin and streptomycin, which are effective only in prokaryote, did not influence aflatoxin production or fungal growth.

\section{Effects of BcA and BcS on A. flavus proteome}

Proteome experiments with $A$. flavus, whose genome sequence has been clarified, were done next. $\mathrm{BcA}$ and $\mathrm{BcS}$ inhibited aflatoxin production of $A$. flavus ( $\mathrm{IC}_{50} 0.25$ and $28 \mu \mathrm{M}$, respectively) with selectivity ( $\mathrm{IC}_{50}$ for growth $1.6 \mu \mathrm{M}$ and $>1000 \mu \mathrm{M}$, respectively), similarly to the case of $A$. parasiticus. A. flavus was cultured with $\mathrm{BcA}(0.3 \mu \mathrm{M})$ or $\mathrm{BcS}(300 \mu \mathrm{M})$ for $24 \mathrm{~h}$ (before onset of aflatoxin production) or $36 \mathrm{~h}$ (after onset of aflatoxin production), and proteins 


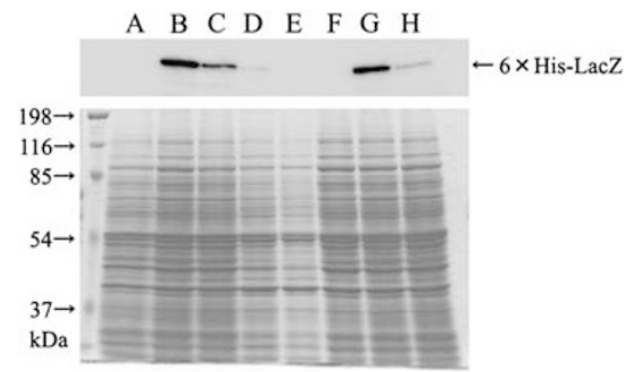

Figure 3 Inhibition of $S$. cerevisiae protein synthesis in the galactoseinduction system. Cell extracts were analyzed by immunoblotting with anti-6xHis antibody (upper panel) or SDS-PAGE after CBB staining (lower panel). Lane A: no galactose (negative control); lane B: no drug (positive control); lane C: $0.1 \mu \mathrm{m}$ blasticidin $\mathrm{A}$; lane $\mathrm{D}: 0.3 \mu \mathrm{m}$ blasticidin $\mathrm{A}$; lane $\mathrm{E}: 1 \mu \mathrm{m}$ blasticidin $\mathrm{A}$; lane $\mathrm{F}: 3 \mu \mathrm{m}$ cycloheximide; lane $\mathrm{G}: 1 \mu \mathrm{m}$ amphotericin B; lane $\mathrm{H}: 300 \mu \mathrm{m}$ blasticidin S.

Table 3 Inhibitory activity of protein synthesis inhibitors against growth and aflatoxin production of $\boldsymbol{A}$. parasiticus

\begin{tabular}{lccc}
\hline & \multicolumn{3}{c}{$I_{50}(\mu \mathrm{m})$} \\
\cline { 2 - 3 } Compound & Aflatoxin $^{\mathrm{a}}$ & \\
\hline Blasticidin A & 0.25 & Growth $(g)$ & $\mathrm{g} / \mathrm{a}^{\mathrm{b}}$ \\
Blasticidin S & 28 & 1.6 & 6.4 \\
G418 & 20 & $>1000$ & $>36$ \\
Cycloheximide & 26 & 160 & 8.0 \\
Chloramphenicol & $>3000$ & 36 & 1.4 \\
Neomycin & $>1600$ & $>3000$ & \\
Streptomycin & $>1700$ & $>1600$ & \\
\hline
\end{tabular}

This aflatoxin means total of aflatoxin $B_{1}$ and $G_{1}$, which are the major detectable aflatoxins produced by the fungus.

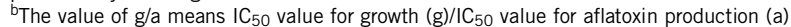

extracted from the mycelia were analyzed by 2D-DIGE (Supplementary Figure S2). We identified 5, 13 and 20 proteins whose abundance levels were changed after $24 \mathrm{~h} \mathrm{BcA}$ treatment, $36 \mathrm{~h} \mathrm{BcA}$ treatment and $36 \mathrm{~h} \mathrm{BcS}$ treatment, respectively (Table 2). Decreased abundances of aflatoxin biosynthetic enzymes (Vbs, OmtB, OmtA, NorA, Ver-1, Nor1) were observed after $36 \mathrm{~h}$ treatment with $\mathrm{BcA}$ or BcS. Abundance levels of proteins in spots 7-11 (Table 2) were also decreased with both $\mathrm{BcA}$ and $\mathrm{BcS}$ treatment. Significant decreased levels of proteins in spots 7 and 8 were also observed with $24 \mathrm{~h} \mathrm{BcA}$ treatment. Functions of most of these proteins are unclear, but they and proteins obtained by further proteome analysis might afford a clue to investigate the regulatory mechanism for aflatoxin production.

Our results strongly suggest that protein synthesis inhibition is a key mode of action of BcA for its antimicrobial activity toward the yeast. It is not clear whether protein synthesis inhibitory activity of $\mathrm{BcA}$ causes selective inhibition of aflatoxin production in fungi, but we found the selective inhibition of BcS and G418 toward the aflatoxin production. Toxicity of BcS has been examined thoroughly and BsA had been practically used in agriculture as an anti-rice blight drug for more than last four decades. Therefore, BcS may be a candidate or lead compound as an effective drug for preventing foods and feeds from aflatoxin contamination. Although it is unclear whether the different effects of BcS, G418 and cycloheximide on aflatoxin production were due to their different modes of inhibition of protein synthesis, our results clearly showed that protein synthesis is a possible target for developing useful aflatoxin production inhibitors.

1 Bennett, J. W. \& Klich, M. Mycotoxins. Clin. Microbiol. Rev. 16, 497-516 (2003).

2 Richard, J. L. \& Payne, G. A. Mycotoxins: Risks in Plant and Animal Systems (Council for Agricultural Science and Technology Press, Ames, IA, 2003).

3 Yoshinari, T. et al. Dioctatin A is a strong inhibitor of aflatoxin production by Aspergillusparasiticus. Microbiology 153, 2774-2780 (2007).

4 Fukunaga, K., Misato, T., Ishii, I. \& Asakawa, M. Blasticidin, a new anti-phytopathogenic fungal substance. Part I. Bull. Agr. Chem. Soc. Jpn. 19, 181-188 (1958).

5 Kono, Y., Takeuchi, S. \& Yonehara, H. Studies on blasticidin A. J. Antibiot. 21, 433-438 (1968)

6 Sakuda, S. et al. Blasticidin A as an inhibitor of aflatoxin production by Aspergillus parasiticus. J. Antibiot. 53, 1265-1271 (2000).

7 Sakuda, S., Matsumori, N., Furihata, K. \& Nagasawa, H. Assignment of the absolute configuration of blasticidin A and revision of that of aflastatin A. Tetrahedron Lett. 48, 2527-2531 (2007).

8 Sakuda, S. et al. Aflastatin A, a novel inhibitor of aflatoxin production of Aspergillusparasiticus, from Streptomyces. J. Am. Chem. Soc. 118, 7855-7856 (1996).

9 Kondo, T. et al. Effects of aflastatin A, an inhibitor of aflatoxin production, on aflatoxin biosynthetic pathway and glucose metabolism in Aspergillusparasiticus. J. Antibiot. 54, 650-657 (2001).

10 Sakuda, S. et al. Blasticidin A derivatives with highly specific inhibitory activity toward aflatoxin production in Aspergillusparasiticus. J. Antibiot. 53, 1378-1384 (2000).

11 Marough, R., David, S. \& Hawkins, E. The development of the DIGE system: 2D fluorescence difference gel analysis technology. Anal. Bioanal. Chem. 382, 669-678 (2005).

12 Pham, T. K. \& Wright, P. C. Proteomics analysis of Saccharomyces cerevisiae. Expert. Rev. Proteomics 4, 793-813 (2007).

13 Teixeira, M. C., Santos, P. M., Fernandes, A. R. \& Sa-Correia, I. A. Proteome analysis of the yeast response to the herbicide 2,4-dichlorophenoxyacetic acid. Proteomics 5, 1889-1901 (2005).

14 Yoshinari, T. et al. Spiroethers of German chamomile inhibit production of aflatoxin $\mathrm{G}_{1}$ and trichothecene mycotoxin by inhibiting cytochrome P450 monooxygenases involved in their biosynthesis. FEMS Microbiol. Lett. 284, 184-190 (2008).

15 Kato-Homma, M. et al. CK2 phosphorylation of eukaryotic translation initiation factor 5 potentiates cell cycle progression. Proc. Natl Acad. Sci. USA 102, 15688-15693 (2005).

16 Gyenis, L. \& Litchfield, D. W. The emerging CK2 interactome: insights into the regulation and functions of CK2. Mol. Cell Biochem. 316, 5-14 (2008).

17 Inoki, K., Ouyang, H., Li, Y. \& Guan, K. L. Signaling by target of rapamycin proteins in cell growth control. Microbiol. Mol. Biol. Rev. 69, 79-100 (2005).

18 Albertyn, J., Hohmann, S., Thevelein, J. M. \& Prior, B. A. GPD1, which encodes glycerol-3-phosphate dehydrogenase, is essential for growth under osmotic stress in Saccharomyces cerevisiae, and its expression is regulated by the high-osmolarity glycerol response pathway. Mol. Cell Biol. 14, 4135-4144 (1994).

19 Hawle, P. et al. Cdc37p is required for stress-induced high-osmolarity glycerol and protein kinase $C$ mitogen-activated protein kinase pathway functionality by interaction with Hog1p and SIt2p (Mpk1p). Eukaryot. Cell 6, 521-532 (2007).

20 Warner, J. R. The economics of ribosome biosynthesis in yeast. Trends Biochem. Sci. 24, 437-440 (1999).

21 Gautschi, M. et al. RAC, a stable ribosome-associated complex in yeast formed by the DnaK-DnaJ homologs Sssz1p and zuotin. Proc. Natl Acad. Sci. USA 98, 3762-3767 (2001).

22 Kallmeyer, A. K., Keeling, K. M. \& Bedwell, D. M. Eukaryotic release factor 1 phosphorylation by CK2 protein kinase is dynamic but has little effect on the efficiency of translation termination in Saccharomyces cerevisiae. Eukaryot. Cell 5, 1378-1387 (2006).

Supplementary Information accompanies the paper on The Journal of Antibiotics website (http://www.nature.com/ja) 